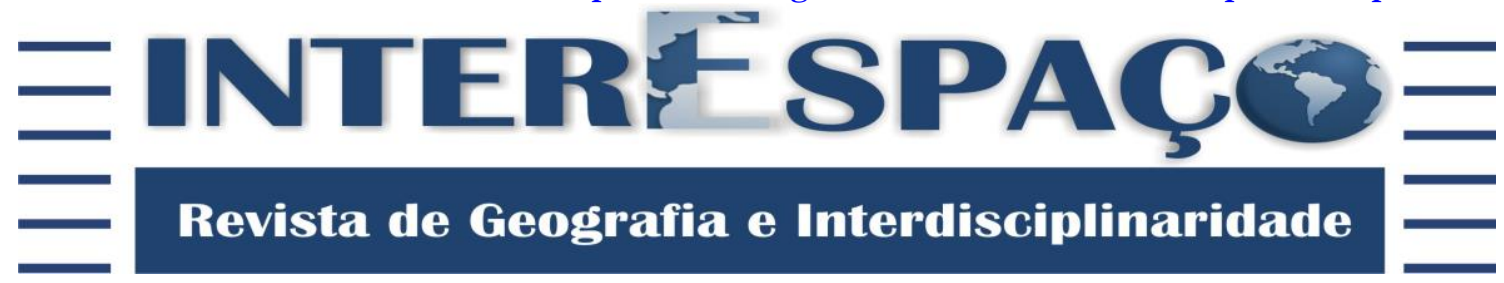

\section{EFECTOS DE EVENTOS EL NIÑO Y LA NIÑA SOBRE LAS LAGUNAS DEL SUR DE LA REGIÓN PAMPEANA (ARGENTINA)}

\author{
Federico Ferrelli \\ Doctor en Geografía recibido en la Universidad Nacional del Sur - UNS. \\ Instituto Argentino de Oceanografía. Consejo Nacional de Investigaciones Científicas \\ y Técnicas (IADO-CONICET). \\ fferrelli@criba.edu.ar
}

\section{RESUMEN}

En este trabajo se estudiaron los efectos de eventos El Niño y La Niña sobre la distribución espacio-temporal de las precipitaciones y el agua superficial en el sur de la Región Pampeana, Argentina. Para ello, se analizaron series mensuales de precipitación con el método de Quintiles, el de la tendencia central o la Normal y el Índice Estandarizado de Precipitación. Se evidenció una relación entre la variabilidad pluviométrica con la ocurrencia de eventos El Niño y La Niña. A partir de entonces se analizaron los impactos de los mismos sobre el agua superficial. Durante un año seco, el número de cuerpos de agua mayores a $2 \mathrm{~km}^{2}$ fue 6 veces menor que durante uno húmedo. La información obtenida en este trabajo constituye una herramienta que contribuiría a estudios ambientales y aportaría información para orientar las políticas de ordenamiento sustentable del territorio.

Palabras clave: Variabilidad Pluviométrica; El Niño; La Niña; Variación del Agua Superficial.

\section{EFFECTS OF EL NIÑO AND LA NIÑA EVENTS ON SHALLOW LAKES LOCATED IN THE SOUTHERN PAMPAS (ARGENTINA)}

\section{ABSTRACT}

In this study, the effects of El Niño and La Niña events were studied considering a spatial and temporal distribution of rainfall and surface water in the south of the Pampas, Argentina . To carry it out, monthly series of precipitation were analyzed by the method of Quintiles, the central tendency or Normal and Standardized Precipitation Index. An evident relationship arise between rainfall variability and the occurrence of El Niño and La Niña. On the other hand, taking into account the impacts on surface water during a dry year, the number of water bodies larger than 2 $\mathrm{km}^{2}$ was six times less than during a wet one. The information obtained in this work represent a tool that will help environmental studies and provide information to guide policies for sustainable land management.

Keywords: Rainfall Variability; El Niño; La Niña; Variation of Surface Water.

\section{EFEITOS DOS EVENTOS EL NIÑO E LA NIÑA SOBRE OS LAGOS DO SUL DA REGIÃO PAMPEANA (ARGENTINA)}

\section{RESUMO}

Neste trabalho foram estudados os efeitos do El Niño e da La Niña sobre a distribuição espaço-temporal das precipitações e da água de superfície no sul da 
Região Pampeana da Argentina. Para tanto, analisaram-se as séries mensais de precipitação com base no método de Quintiles, a tendência central ou normal e o Índice Padronizado de Precipitação. Identificou-se uma relação entre a variabilidade da precipitação com a ocorrência dos eventos El Niño e La Niña. Posteriormente, analisaram-se os impactos dos mesmos sobre a água superficial. Durante um ano seco, o número de corpos d'água maiores do que $2 \mathrm{~km}^{2}$ foi 6 vezes menor que durante um ano úmido. As informações obtidas neste trabalho constituem uma ferramenta que pode contribuir na realização de estudos ambientais e fornecer informações para orientar as políticas de ordenamento sustentável do território.

Palavras-chave: Variabilidade Pluviométrica; El Niño; La Niña; Variação das Águas Superficiais.

\section{INTRODUCCIÓN}

Los estudios sobre la disponibilidad de agua y su distribución espacio-temporal así como también el análisis de los riesgos de sequías e inundaciones son de gran relevancia para preservar la calidad de vida de la población y el ambiente (LEHNER et al., 2006). El estudio del clima es un factor clave para determinar las diferentes características y distribución de los recursos hídricos de origen natural. En este contexto, la precipitación y su variabilidad, definen ciclos estacionales así como también variaciones interanuales en sus regímenes (ALIAGA et al., 2016a).

Como consecuencia de la variabilidad climática, la mayor parte de las cuencas del mundo han experimentado cambios en el caudal y/o modificado los servicios ecosistémicos que ofrecen (PALMER et al., 2008). A partir de este conocimiento, el estudio de ellas y de los reservorios de agua han sido objeto de numerosos trabajos (p.e. BOHN et al., 2016) en los cuales se asocia la variación espacio-temporal de distintos cuerpos de agua con las fluctuaciones pluviométricas y con la ocurrencia de eventos El Niño o La Niña.

Los cuerpos de agua de menor profundidad están menos influenciados por los escenarios climáticos pasados que los profundos, o sea que responden a las situaciones meteorológicas presentes (GERTEN; ADRIAN, 2000, 2001). Sin embargo, la morfometría de un cuerpo de agua y sus condiciones de sitio, determinan un efecto particular del clima sobre las variables ambientales de los mismos (GERTEN; ADRIAN, 2001; MOOIJ et al., 2005).

Para el monitoreo de la disponibilidad de agua superficial, adquiere importancia la teledetección (CHUVIECO; 2002; NOSETTO et al., 2005; GORDON et al., 2008). La reflectividad de la superficie terrestre es un indicador de diferentes características y del estado de los recursos naturales siendo el agua uno de los más variables en el tiempo (CHUVIECO, 2002). 
Efectos de eventos El Niño y La Niña sobre las lagunas del sur de la Región Pampeana (Argentina) Federico Ferrelli

Está demostrado que las zonas secas de la Región Pampeana tienen menor número de eventos pluviométricos extremos pero de mayor intensidad (ALIAGA et al., 2016a). Esta zona es propensa a variaciones pluviométricas que podrían ser el resultado de la ocurrencia de eventos El Niño y La Niña. En este área se desconocen los efectos sobre la disponibilidad de agua superficial. Por tal motivo, el objetivo de este trabajo fue analizar la periodicidad, frecuencia y duración de las sequías e inundaciones que se presentaron en las zonas secas de la Región Pampeana y los efectos sobre la disponibilidad de agua durante eventos El Niño y La Niña. La ejecución de un estudio a escala regional con datos meteorológicos actualizados junto con el conocimiento de la dinámica espacio-temporal de los cuerpos de agua podría contribuir a mejorar la utilización del recurso en aquellas zonas vulnerables a la erosión eólica y/o hídrica que repercuten en la pérdida de ganado y cosechas.

\section{ÁREA DE ESTUDIO}

El área de estudio de este trabajo corresponde al sur de la provincia de Buenos Aires, Argentina, determinada como las subregiones pampeanas Seca y Muy Seca por Aliaga et al., (2016a). Incorpora los partidos de Villarino y Patagones que abarcan un total de 2,6 millones de ha (Figura 1). Las condiciones edáficas determinan suelos de tipo molisoles y entisoles aptos para el desarrollo de actividades agrícolas (SANCHEZ et al., 1998). En general, su clima es templado-árido en el que la aridez se incrementa de norte a sur. 


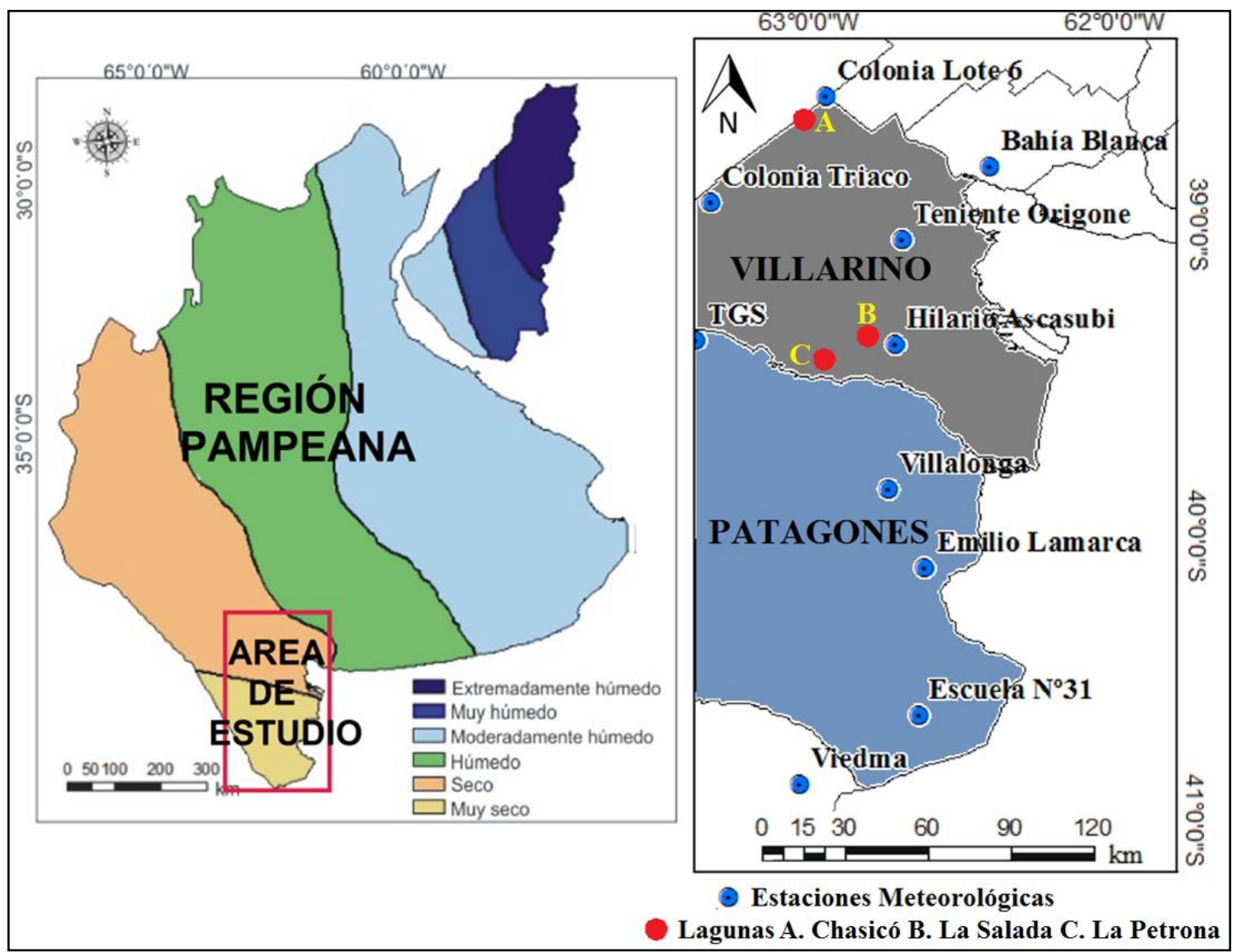

Figura 1 - Localización del área de estudio

Fuente: Modificado de FERRELLI; ALIAGA (2015).

El área de estudio presenta grandes fluctuaciones pluviométricas que impactan sobre las actividades agropecuarias de la población. El comportamiento normal de las precipitaciones presenta mayoritariamente déficit hídrico en la mayor parte del año (FERRELLI et al., 2012). Los cuerpos de agua superficiales son principalmente cubetas eólicas de escasa profundidad caracterizadas por estar influenciadas por las variaciones pluviométricas presentes (FERRELLI et al., 2011). Además, existen lagunas como Chasicó que es de origen tectónico y La Salada cuyo caudal es manejado antrópicamente (Figura 1).

\section{METODOLOGÍA}

Se analizaron los efectos sobre la precipitación durante un evento La Niña de intensidad moderada ocurrido entre 2007-2009 y otro evento El Niño muy intenso en 2014-2015 determinados por el Centro de Predicción Climática de Estados Unidos (http://www.cpc.ncep.noaa.gov/). A partir del conocimiento de la ocurrencia de ellos, se procedió a evaluar los impactos sobre la disponibilidad de agua. Se consideró "cuerpos de agua superficiales" a aquellas cubetas de agua que estuvieron presentes sobre la superficie 
Efectos de eventos El Niño y La Niña sobre las lagunas del sur de la Región Pampeana (Argentina)

del área de estudio en tres momentos determinados: 2009 (sequía-La Niña), 2011 (período de precipitaciones normal) y 2014 (período muy lluvioso-El Niño). Dentro de ellos se incorporaron sólo a los mayores a 50 ha para evitar los errores propios de las estimaciones del área con imágenes satelitales LANDSAT que es de $40 \mathrm{~m}^{2}$ (ALIAGA et al., 2016b). No se consideraron los ríos en esta investigación dado que los cauces, muchas veces presentes con suelos húmedos, podrían generar una sobreestimación del área.

Por otro lado, la variabilidad pluviométrica se analizó con datos de precipitación de diez estaciones pertenecientes al Servicio Meteorológico Nacional (SMN, Argentina), al Instituto Nacional de Tecnología Agropecuaria (INTA, Argentina) y a la Red de Información Agroeconómica Pampeana (INTA-RIAP) (Figura 1). El período de estudio fue 1966-2015 para la estación Bahía Blanca (representativa del norte), Hilario Ascasubi (del centro) y Viedma (sur). El período de estudio de las estaciones correspondientes al INTA-RIAP fue 2003-2015 (Tabla 1). Para calcular las anomalías pluviométricas, los datos de estas últimas se compararon con los valores medios obtenidos para el norte, centro y sur considerando el método del vecino más próximo. La calidad de los datos meteorológicos para este área fue probada por ALIAGA et al. (2016a) y aplicada en estudios como el de FERRELLI et al. (2016).

Tabla 1 - Estaciones meteorológicas utilizadas, período de estudio, fuente y localización

\begin{tabular}{|l|c|c|c|c|}
\hline \multicolumn{1}{|c|}{ Estaciones } & Latitud & Longitud & Fuente & Período de estudio \\
\hline Viedma & -40.975 & -63.061 & SMN & $1966-2015$ \\
\hline Escuela No31 & -40.656 & -62.548 & INTA-RIAP & $2003-2015$ \\
\hline Villalonga & -39.915 & -62.619 & INTA-RIAP & $2004-2015$ \\
\hline Hilario Ascasubi & -39.381 & -62.640 & INTA & $1966-2015$ \\
\hline TGS & -39.367 & -63.379 & INTA-RIAP & $2003-2015$ \\
\hline Teniente Origone & -38.993 & -62.613 & INTA-RIAP & $2003-2015$ \\
\hline Emilio Lamarca & -40.187 & -62.606 & INTA-RIAP & $2003-2015$ \\
\hline Colonia Triaco & -38.812 & -63.619 & INTA-RIAP & $2003-2015$ \\
\hline Colonia Lote 6 & -38.449 & -63.081 & INTA-RIAP & $2003-2015$ \\
\hline Bahía Blanca & -38.729 & -62.261 & SMN & $1966-2015$ \\
\hline
\end{tabular}

Fuente: Elaboración propia.

Los datos se analizaron considerando las líneas de tendencias central o los valores medios (Método de la Normal), el Método de Quintiles (BOLOGNESI, 1971) y el Índice Estandarizado de Precipitación (IEP) (EDWARDS; MCKEE, 1997). El Método de Quintiles y el IEP permitieron discriminar los eventos húmedos y secos según los criterios 
Efectos de eventos El Niño y La Niña sobre las lagunas del sur de la Región Pampeana (Argentina)

presentados en la Tabla 2. El primero de ellos se calculó teniendo en cuanta la siguiente ecuación:

$$
Q_{k}=\frac{k_{n}}{5}
$$

donde $k$ es el orden del quintil $(\mathrm{k}=1,2,3,4)$ y $n$ es el número de observaciones.

Por otro lado, con el IEP se estudió la intensidad y duración de los eventos secos y húmedos ocurridos como consecuencia de los eventos El Niño y La Niña. Se aplicó en tres escalas temporales: mensual, estacional y anual. Para ello, se transformaron las series mensuales de precipitación con media 0 y desvío 1, considerando una distribución normal. De esta manera se cuantificó la duración (en meses) de cada evento y se calculó su intensidad media. Esta forma de estudiar las sequías e inundaciones se ha aplicado en otras partes del mundo con éxito, son ejemplos MOREIRA et al., (2006); ZHANG et al., (2009) y ZHAI et al., (2010).

Tabla 2 - Caracterización de los eventos pluviométricos según el IEP y el Método de Quintiles

\begin{tabular}{|c|c|c|c|}
\hline \multicolumn{2}{|c|}{ Método de Quintiles } & \multicolumn{2}{|c|}{ Índice Estandarizado de Precipitación } \\
\hline \multirow{2}{*}{ Muy Seco } & \multirow{2}{*}{$\mathrm{P}<1 \mathrm{Q}$} & Extremadamente seco & $<-2$ \\
\hline & & Muy Seco & $>-1.5<-2$ \\
\hline Seco & $1 \mathrm{Q} \leq \mathrm{P}<2 \mathrm{Q}$ & Seco & $>-1<-1.5$ \\
\hline Normal & $2 \mathrm{Q} \leq \mathrm{P}<3 \mathrm{Q}$ & Normal & $<1>-1$ \\
\hline Lluvioso & $3 \mathrm{Q} \leq \mathrm{P}<4 \mathrm{Q}$ & Húmedo & $>1<1.5$ \\
\hline \multirow{2}{*}{ Muy Lluvioso } & \multirow{2}{*}{$P \geq 4 Q$} & Muy Húmedo & $>1.5<2$ \\
\hline & & Extremadamente Húmedo & $>2$ \\
\hline
\end{tabular}

Fuente: Modificado de BOLOGNESI (1971) y EDWARDS; MCKEE (1997).

Por otro lado, la variación del área de los cuerpos de agua superficiales se calculó a partir del procesamiento digital de imágenes satelitales LANDSAT 5 TM y 8 OLI-TIRS (Tabla 3). Se utilizaron sólo imágenes LANDSAT 5 TM y 8 OLI debido a que el LANDSAT 7 ETM+ tiene un error de barrido que dificulta este tipo de estudios. Las fechas de las mismas fueron las más próximas al final del año o al principio del año próximo para considerar los efectos sobre los cuerpos de agua superficiales de la precipitación anual durante los eventos considerados: El Niño, La Niña y un período normal. En una primera etapa las mismas fueron calibradas geométrica y radiométricamente. El procesamiento digital de las imágenes satelitales se realizó considerando la metodología detallada por FERRELLI et al., (2015) y ALIAGA et al., (2016b). 
Efectos de eventos El Niño y La Niña sobre las lagunas del sur de la Región Pampeana (Argentina) Federico Ferrelli

Tabla 3 - Imágenes satelitales utilizadas en este estudio

\begin{tabular}{|c|c|c|c|}
\hline Satélite & Fecha & Año pluviométrico & Path-Row \\
\hline LANDSAT 5 TM & 11 de diciembre de 2009 & Seco & $226-087$ \\
\hline LANDSAT 5 TM & 11 de diciembre de 2009 & Seco & $226-088$ \\
\hline LANDSAT 5 TM & 20 de enero de 2010 & Seco & $227-087$ \\
\hline LANDSAT 5 TM & 20 de enero de 2010 & Seco & $227-088$ \\
\hline LANDSAT 5 TM & 21 de octubre de 2011 & Normal & $227-087$ \\
\hline LANDSAT 5 TM & 21 de octubre de 2011 & Normal & $227-088$ \\
\hline LANDSAT 5 TM & 30 de octubre de 2011 & Normal & $226-087$ \\
\hline LANDSAT 5 TM & 30 de octubre de 2011 & Normal & $226-088$ \\
\hline LANDSAT 8 OLI & 11 de enero de 2015 & Húmedo & $226-087$ \\
\hline LANDSAT 8 OLI & 11 de enero de 2015 & Húmedo & $226-088$ \\
\hline LANDSAT 8 OLI & 15 de enero de 2015 & Húmedo & $227-087$ \\
\hline LANDSAT 8 OLI & 15 de enero de 2015 & Húmedo & $227-088$ \\
\hline
\end{tabular}

Fuente: Elaboración propia.

Las imágenes satelitales fueron corregidas geométricamente con la técnica de puntos de control (CARMONA et al., 2011). Posteriormente se realizó una calibración radiométrica para convertir los valores digitales a valores de radiancia. En las bandas 1-4 de LANDSAT 5 TM y 1-5 de LANDSAT 8 OLI los efectos atmosféricos de dispersión no pueden despreciarse y por ello se estima la reflectividad considerando el método de Resta de Superficies Oscuras (SONG et al., 2001). Una vez calibradas, se aplicó una clasificación no supervisada del tipo Interactive Self-Organizing Data Analysis Technique Algorithm (ISODATA) (SWAIN, 1973) sobre las cuatro primeras bandas del LANDSAT 5 TM y las cinco primeras del LANDSAT 8 OLI (Visible e Infrarrojo Cercano -IRC-). El mismo permitió diferenciar el agua de la superficie terrestres debido a sus diferentes características radiativas (p.e. DÍAZ DE ARCAYA et al., 2005; ALIAGA et al., 2016b). En este análisis se consideraron como ejemplo tres lagunas de distintos orígenes: Chasicó, de origen tectónico, con una profundidad de $20 \mathrm{~m}$ y aportes de agua subterránea; La Salada influenciada por el manejo humano, con aportes de agua y manejo del caudal y La Petrona que es una cubeta de origen eólico representativa de las típicas lagunas pampeanas (Figura 1) (ALIAGA et al., 2016b).

\section{RESULTADOS Y DISCUSIÓN}

\section{Análisis de las precipitaciones}


Efectos de eventos El Niño y La Niña sobre las lagunas del sur de la Región Pampeana (Argentina) Federico Ferrelli

Las precipitaciones son mayores en el norte y decrecen hacia el sur. En Bahía Blanca el valor medio para el período 1966-2015 es 644,6 mm anuales, en Hilario Ascasubi $495 \mathrm{~mm}$ y en Viedma $370 \mathrm{~mm}$. Los mayores registros de precipitación se presentan en el verano, seguidos por la primavera y en menor medida en otoño e invierno (Figura 2).

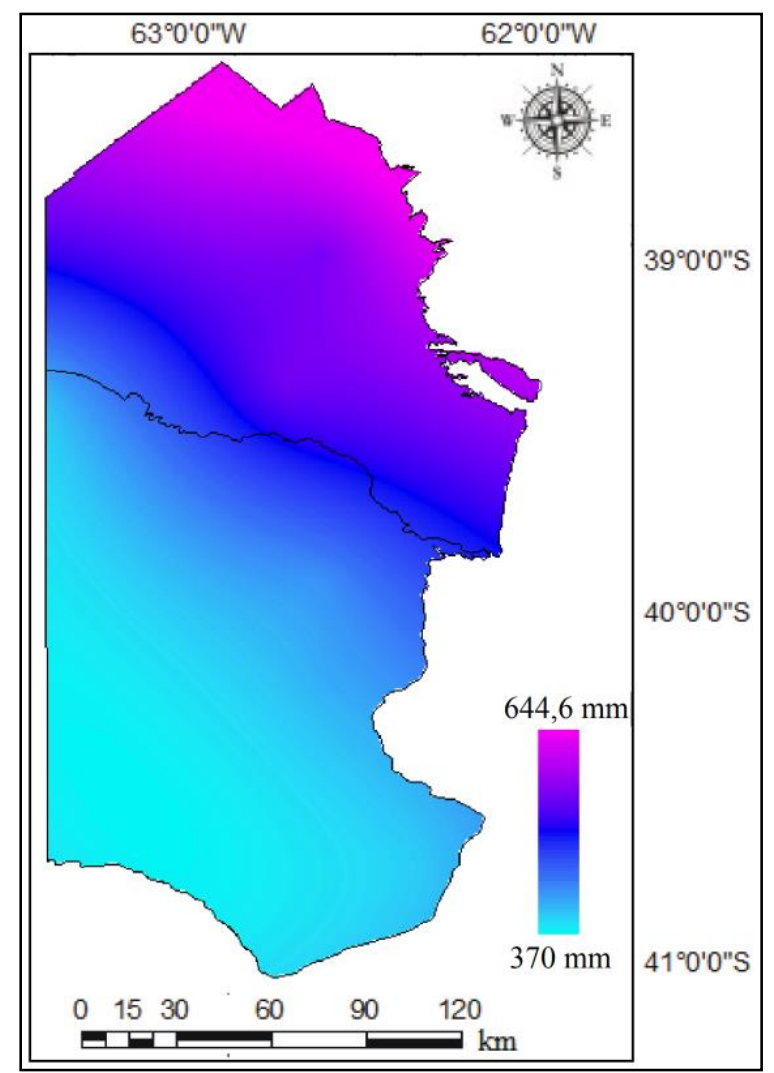

Figura 2 - Distribución espacial de las precipitaciones Fuente: Elaboración propia.

Según ALIAGA et al., (2016a) esta región corresponde a las zonas Seca y Muy Seca de la región pampeana. Las mismas se caracterizan por presentar una variación estacional e inter-anual de las precipitaciones con períodos secos de mayor intensidad. La variabilidad de las precipitaciones genera impactos sobre la distribución espacio-temporal de los cuerpos de agua en distintos eventos pluviométricos extremos (ALIAGA et al., 2016b). Sobre esta región las sequías tienen más periodicidad que los eventos lluviosos. El período 1921-1955 se caracterizó por presentar mayor número de eventos secos que el de 19682009 (FERRELLI et al., 2012).

En el norte de la región se observaron sucesiones de eventos secos y húmedos. En Bahía Blanca los períodos secos coincidieron con eventos La Niña y los húmedos con El Niño. La Niña ocurrido en 2007-2009, de carácter severo, ocasionó que en esta región se produjera un evento Extremadamente Seco (IEP = -2,11). Esta sequía se extendió durante 
Efectos de eventos El Niño y La Niña sobre las lagunas del sur de la Región Pampeana (Argentina) Federico Ferrelli

16 meses, desde agosto de 2008 hasta diciembre de 2009. El Niño ocasionó un período Húmedo que se duró 8 meses (IEP = 1,1) (Figura 3.1). En este contexto, se concuerda con autores como ACEITUNO (1988) y GRIMM et al. (2000) ya que afirman que América del Sur es altamente influenciada por el fenómeno de El Niño Oscilación Sur (en inglés, El Niño Southern Oscillation, ENSO), siendo un importante factor de variabilidad climática interanual. Además, otros estudios han demostrado que la provincia de Buenos Aires experimenta eventos lluviosos en períodos El Niño mientras que muestra eventos secos durante La Niña (SCIAN, 2002, 2006; FERRELLI; ALIAGA, 2015). Hay evidencias que en la mitad de los casos estudiados, los eventos El Niño son precedidos por un evento La Niña (DELGADO, 2013).

En el centro de la región, representada por la estación Hilario Ascasubi, se presentaron dos eventos Extremadamente Secos en 1989 y 2009. El evento El Niño de 2014-2015 produjo un período con precipitaciones elevadas de 7 meses de duración (IEP = 1,32), mientras que La Niña 2007-2009 ocasionó la sequía más severa de la región desde que se tienen registros meteorológicos (FERRELLI, 2012). La misma se extendió durante 26 meses (IEP = -2,3) desde marzo de 2008 hasta enero de 2010 (Figura 3.2).

En el sur de la región, representado por la estación de Viedma, se observó un comportamiento pluviométrico similar al del resto de las estaciones analizadas. El evento El Niño generó un período Muy Húmedo que se extendió durante 13 meses desde agosto de 2014 hasta agosto de 2015 (IEP = 1,73). Por otro lado, el evento La Niña generó una sequía que duró 18 meses desde septiembre de 2008 hasta febrero de 2010 (IEP = -1,67) (Figura 3.3). En toda la región se presentaron en simultáneo los eventos secos y húmedos, exceptuando aquel ocurrido durante 1984-1985 que fue más intenso a medida que aumentó la aridez del ambiente (norte-sur). Se observó que tanto los períodos húmedos como los secos fueron más intensos en el sur que en el norte. 


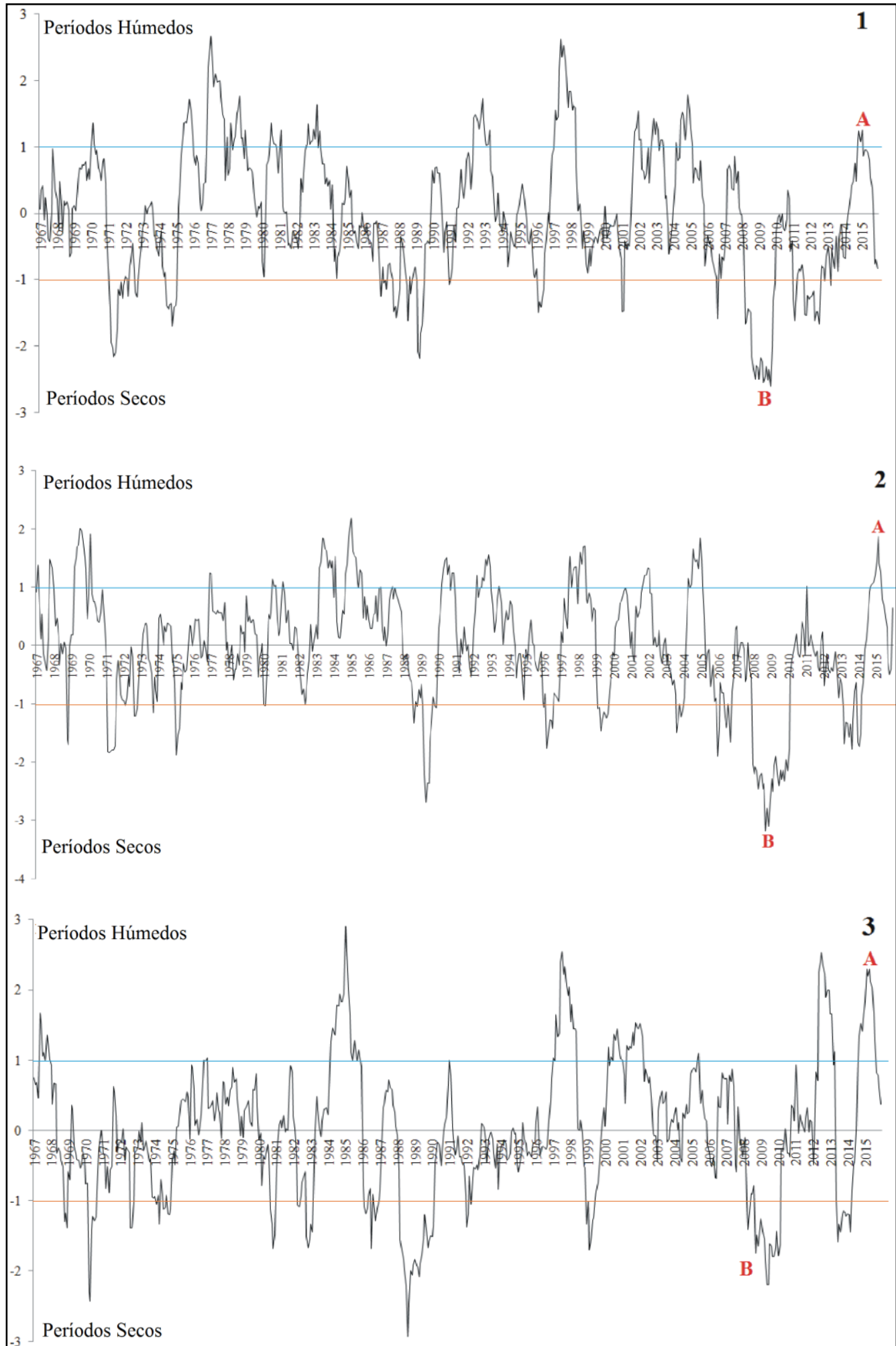

Figura 3 - IEP en 1. Bahía Blanca 2. Hilario Ascasubi y 3. Viedma. A. Evento El Niño severo (20142015) y B. La Niña moderada (2007-2009)

Fuente: Elaboración propia.

\section{Períodos secos y húmedos}


Efectos de eventos El Niño y La Niña sobre las lagunas del sur de la Región Pampeana (Argentina) Federico Ferrelli

El evento La Niña, identificado en el período 2007-2009, generó una disminución de las precipitaciones en todo el área de estudio. Se observó que la sequía originada fue más larga en el centro y noroeste con una duración superior a 2 años. En el sudoeste y noreste el período seco generado osciló entre 16 y 18 meses (Figura 4.1). En lo que respecta a la intensidad de este evento, se observó que el centro de la región y el sudeste fueron las zonas que presentaron sequías más intensas. En estos espacios los eventos fueron Extremadamente Secos según el IEP. En el este y en el sudoeste, fue menos severa (-1,75 -1,5) permitiendo identificar los eventos como Secos y Muy Secos (Figura 4.2). Es importante destacar que el conocimiento de la variabilidad climática de un área es uno de los elementos clave para comprender el funcionamiento de los sistemas naturales y de las actividades humanas. Además, sus efectos sobre las actividades agropecuarias pueden generar cambios en el uso de la tierra e impactos significativos sobre su rendimiento (MAGRIN et al., 2005).

Se identificaron anomalías negativas en toda la extensión del área de estudio durante este evento. Los mayores impactos representaron una franja que se extendió desde el noreste hacia el sudoeste. En ella, las precipitaciones fueron entre 400 a $240 \mathrm{~mm}$ inferiores al valor medio anual. Por otro lado, en el este y sur las anomalías oscilaron entre 160 y $0 \mathrm{~mm}$ (Figura 5).

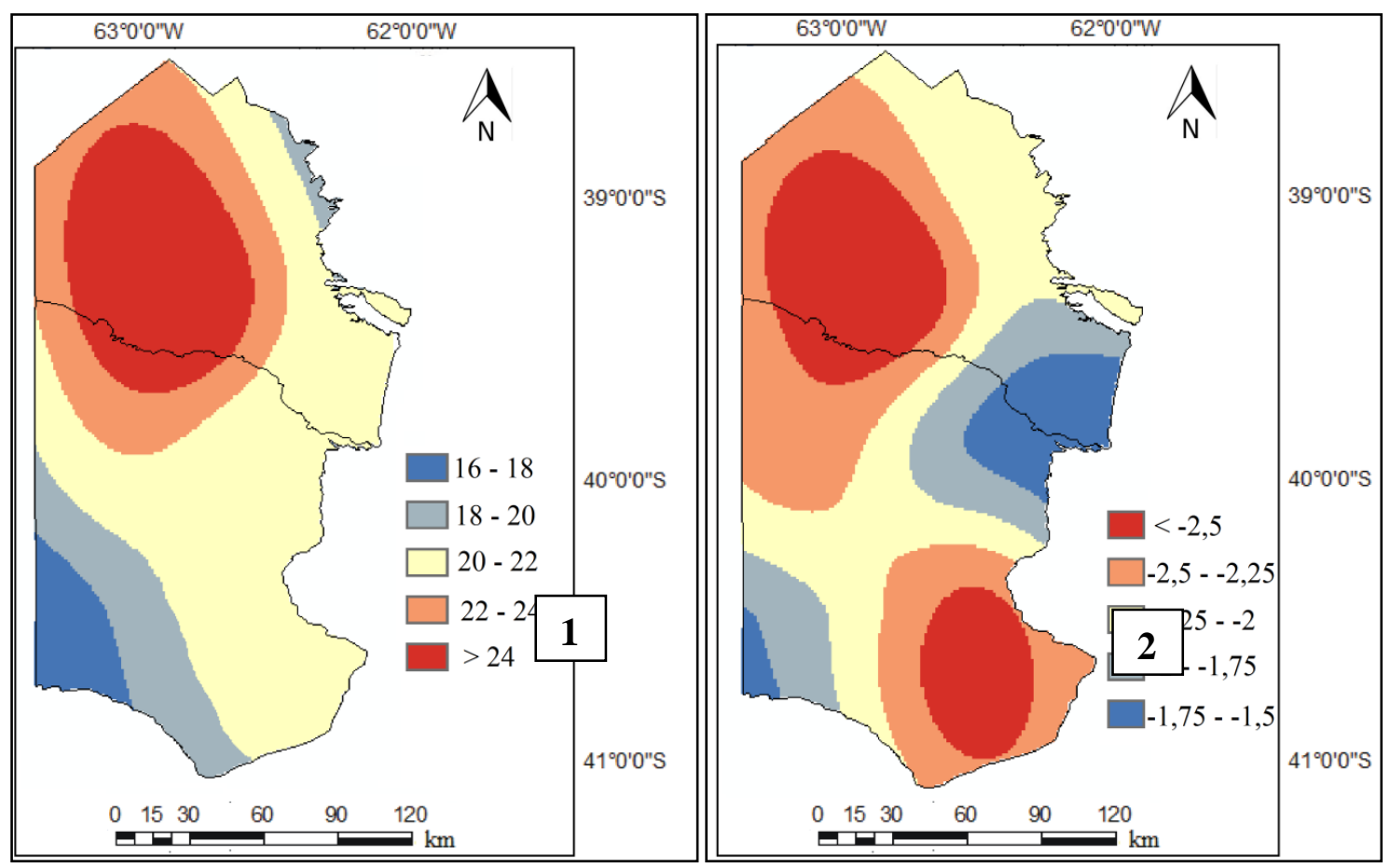

Figura 4 - Duración (meses) (1) e Intensidad (2) de la sequía durante el evento La Niña Fuente: Elaboración propia. 


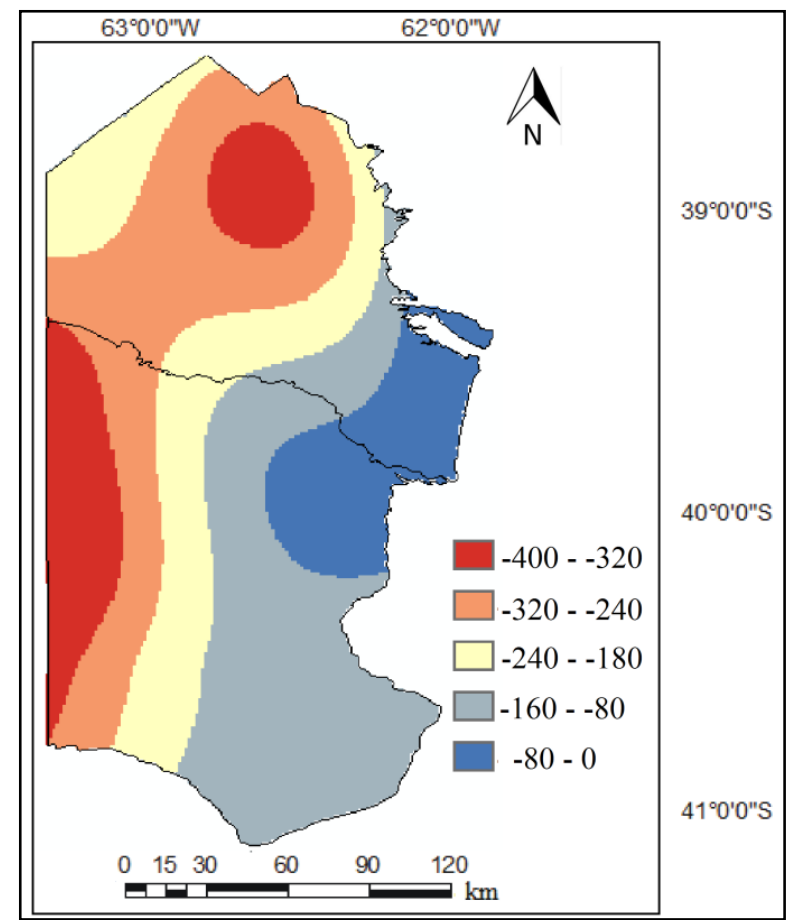

Figura 5 - Anomalías pluviométricas (mm) durante el evento La Niña Fuente: Elaboración propia.

El evento El Niño registrado durante 2014-2015 generó un período húmedo. El mismo tuvo mayor extensión en el sur del área de estudio (12-15 meses). Esta disminuyó en sentido sur-norte llegando a una duración de 3 meses (Figura 6.1). Su intensidad fue distinta: los períodos Muy Húmedos se localizaron en el oeste (IEP = 2) y los Húmedos y Moderadamente Húmedos al este y noreste (IEP 1,5 - 1,8) (Figura 6.2). Es importante considerar la intensidad de los eventos pluviométricos ya que tanto las inundaciones como las sequías afectan las zonas sembradas, la hacienda y las viviendas. Esto causa graves consecuencias socioeconómicas. Entre los efectos sobre la población se destaca la disminución de la accesibilidad al agua potable y la provisión de energía, el acceso a plantas medicinales, desplazamiento y desaparición de animales y recursos pesqueros, entre otros (HOUGHTON, 1993; FERRELLI et al., 2011).

Durante este evento se generaron anomalías positivas de precipitación. Las mayores se observaron en el noreste y sudoeste con $+350 \mathrm{~mm}$. Los menores efectos se calcularon en la zona central representada por la estación de Hilario Ascasubi con un incremento de 100-150 mm. Una situación similar se presentó en el sudeste con 150-200 mm (Figura 7). 


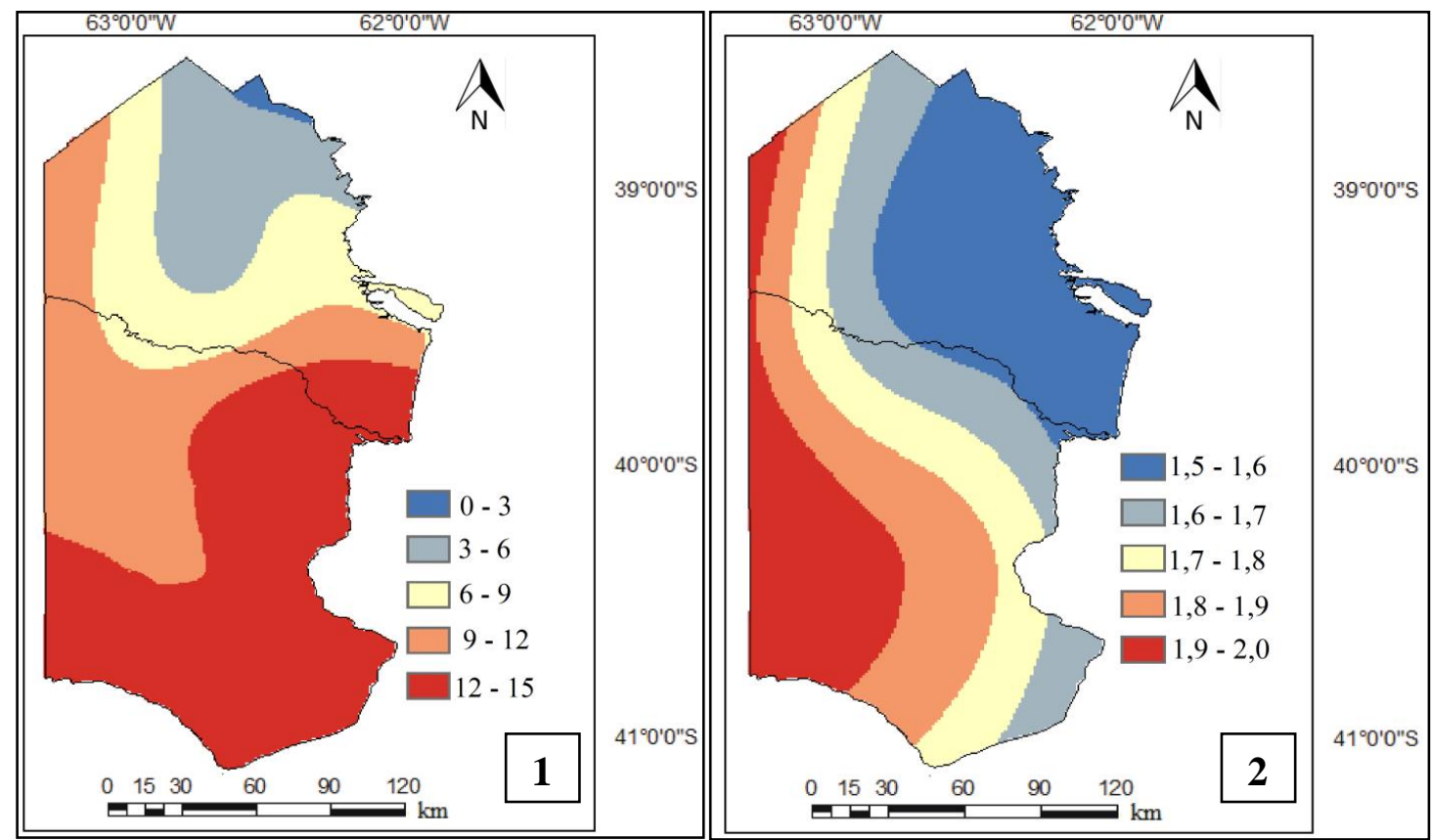

Figura 6-Duración (meses) (1) e Intensidad (2) de la sequía durante el evento El Niño Fuente: Elaboración propia.

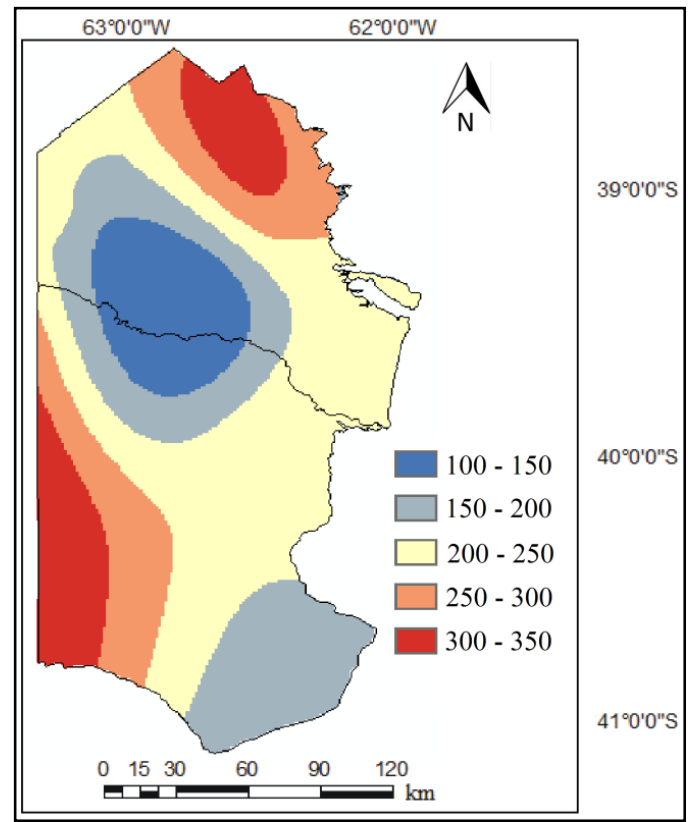

Figura 7 - Anomalías pluviométricas (mm) durante el evento El Niño 2015 Fuente: Elaboración propia.

\section{Efectos sobre el agua superficial}

Para realizar el análisis de los impactos de las precipitaciones sobre los cuerpos de agua se consideraron tres eventos determinados por los métodos de la Normal, Quintiles y el IEP como Normal (Tabla 4), Seco (Tabla 5) y Húmedo (Tabla 6). El primero de ellos corresponde a 2011. Se caracterizó por presentarse durante un evento El Niño de 
Efectos de eventos El Niño y La Niña sobre las lagunas del sur de la Región Pampeana (Argentina)

intensidad débil. Según el método de la normal o comparación de la línea de tendencia central, las estaciones Escuela $N^{0} 31$, Villalonga, TGS y Emilio Lamarca presentaron una precipitación anual superior al valor medio. Sin embargo, las mismas fueron todas correspondientes con años Normales según el método de Quintiles. Por otro lado, el IEP presentó sólo dos situaciones que no fueron normales: en Teniente Origone fue un año Seco y en TGS uno Húmedo (Tabla 4).

Este año presentó un total de $127 \mathrm{~km}^{2}$ de agua superficial, aproximadamente 0,49 $\%$ del área de estudio. Además, se observaron 5 cuerpos de agua mayores a $2 \mathrm{~km}^{2}$ con respecto al año seco (Figura 8). La laguna La Salada mantuvo un área de $3,7 \mathrm{~km}^{2}$, mientras que La Petrona registró un área superior al año seco $\left(2,9 \mathrm{~km}^{2}\right)$. La laguna Chasicó presentó un área de $2 \mathrm{~km}^{2}$ mayor que en el año seco $\left(67,1 \mathrm{~km}^{2}\right)$. La menor cantidad de lagunas se observó en el sur de la región, abarcando un área de $6,7 \mathrm{~km}^{2}$. La cantidad de agua puede tener variaciones en distintas escalas de tiempo. Pueden nombrarse escalas cortas, como tormentas, períodos de semanas y también hay oscilaciones interanuales como consecuencia de las fluctuaciones estacionales. Los niveles de agua también pueden variar como consecuencia de las tendencias estacionales de las precipitaciones (BOHN, 2009).

Tabla 4 - Caracterización de la precipitación en un año normal según los métodos $\mathrm{N}$. relación con la tendencia central (Normal), IEP. Índice Estandarizado de Precipitación, Q. Método de Quintiles

\begin{tabular}{|l|c|c|c|c|}
\hline \multirow{2}{*}{ Estaciones Meteorológicas } & \multicolumn{4}{|c|}{ Año Normal (2011) } \\
\cline { 2 - 5 } & Pp anual & N & IEP & Q \\
\hline Viedma & 370 & Igual & Normal & Normal \\
\hline Escuela No31 & 371 & Inferior & Normal & Normal \\
\hline Villalonga & 405 & Superior & Normal & Normal \\
\hline Hilario Ascasubi & 509 & Superior & Normal & Normal \\
\hline TGS & 721 & Superior & Húmedo & Normal \\
\hline Teniente Origone & 450 & Inferior & seco & Normal \\
\hline Emilio Lamarca & 513 & Superior & Normal & Normal \\
\hline Colonia Triaco & 422 & Inferior & Normal & Normal \\
\hline Colonia Lote 6 & 542 & Superior & Normal & Normal \\
\hline Bahía Blanca & 584 & Inferior & Seco & Normal \\
\hline
\end{tabular}

Fuente: Elaboración propia. 


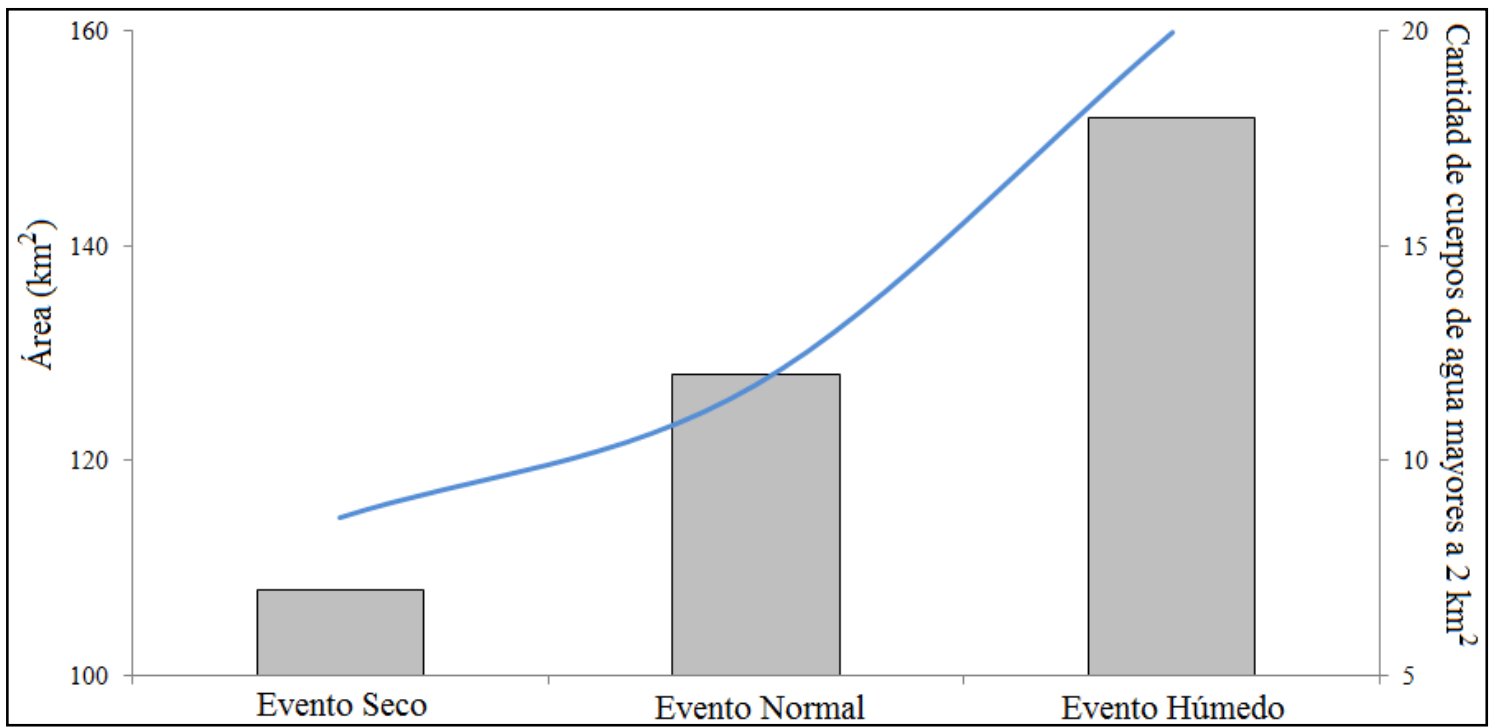

Figura 8 - Variación del área de las lagunas y cantidad de cuerpos de agua mayores a $2 \mathrm{~km}^{2}$ durante distintos eventos pluviométricos

Fuente: Elaboración propia.

El año seco seleccionado fue 2009, coincidente con un evento La Niña. Si bien el mismo comienza en 2007, la mayor intensidad de sequía en la región de estudio se produjo en 2009. Según el método de la Normal, todas las estaciones presentaron una situación de precipitaciones inferior a la esperada (valor medio). El Método de Quintiles caracterizó al año como Muy Seco en toda el área de estudio. El IEP identificó que el año fue Muy Seco en toda la región exceptuando Hilario Ascasubi, Emilio Lamarca, Colonia Triaco y Bahía Blanca en donde se presentó un evento Extremadamente Seco (Tabla 5).

En 2009 se registró una superficie de $114,7 \mathrm{~km}^{2}$ de agua superficial, es decir, el 0,44\% del total de la extensión del área estudiada. El área de las lagunas fue $9,4 \mathrm{~km}^{2}$ menor que el año normal. Se observó que el área de los cuerpos de agua osciló entre $0,1 \mathrm{~km}^{2}$ y $63,1 \mathrm{~km}^{2}$. Se destacaron las lagunas La Salada $\left(3,6 \mathrm{~km}^{2}\right)$, La Petrona $\left(2,2 \mathrm{~km}^{2}\right)$ y Chasicó (65 $\mathrm{km}^{2}$ ). En el sur del área de estudio, los cuerpos de agua superficiales fueron pequeños y escasos con un área total de $5,7 \mathrm{~km}^{2}$ (Figura 8). Es importante destacar que las lagunas localizadas en este área son propensas a sufrir variaciones espacio-temporales como consecuencia de la variabilidad pluviométrica (ALIAGA et al., 2016b). Además, estas variaciones se profundizan debido a que los suelos son de textura franco arenoso y propenso a la erosión hídrica y eólica con bajo contenido de materia orgánica y capacidad de retención hídrica. (FERRELLI et al., 2011). 
Efectos de eventos El Niño y La Niña sobre las lagunas del sur de la Región Pampeana (Argentina)

Tabla 5 - Caracterización de la precipitación en un año seco según los métodos N. relación con la tendencia central (Normal), IEP. Índice Estandarizado de Precipitación, Q. Método de Quintiles

\begin{tabular}{|l|c|c|c|c|}
\hline \multirow{2}{*}{$\begin{array}{c}\text { Estaciones } \\
\text { Meteorológicas }\end{array}$} & \multicolumn{4}{c|}{ Evento La Nina (2009) } \\
\cline { 2 - 5 } & Pp anual & N & IEP & Q \\
\hline Viedma & 213 & Inferior & Muy Seco & Muy Seco \\
\hline Escuela N S1 $^{\text {Ped }}$ & 226 & Inferior & Muy Seco & Muy Seco \\
\hline Villalonga & 214 & Inferior & Muy Seco & Muy Seco \\
\hline Hilario Ascasubi & 288 & Inferior & Extremadamente Seco & Muy Seco \\
\hline TGS & 94 & Inferior & Muy Seco & Muy Seco \\
\hline Teniente Origone & 277 & Inferior & Muy Seco & Muy Seco \\
\hline Emilio Lamarca & 171 & Inferior & Extremadamente Seco & Muy Seco \\
\hline Colonia Triaco & 283 & Inferior & Extremadamente Seco & Muy Seco \\
\hline Colonia Lote 6 & 285 & Inferior & Muy Seco & Muy Seco \\
\hline Bahía Blanca & 500 & Inferior & Extremadamente Seco & Muy Seco \\
\hline
\end{tabular}

Fuente: Elaboración propia.

El año lluvioso correspondió a 2014. El mismo fue superior al valor medio en toda la extensión del área de estudio y Muy Lluvioso según el Método de Quintiles. El IEP identificó un evento Muy Húmedo en toda el área exceptuando Colonia Triaco y Colonia Lote 6 en donde fue Extremadamente Húmedo y Viedma y Escuela No31 en donde fue Húmedo (Tabla 6).

El área total de las lagunas durante el período húmedo fue $159,9 \mathrm{~km}^{2}(0,62 \%$ del área de estudio), es decir, $39 \mathrm{~km}^{2}$ mayor que en el año normal y 45,2 $\mathrm{km}^{2}$ mayor que en el seco. Las lagunas del centro de la región manifestaron un área mayor: La Salada presentó $3,8 \mathrm{~km}^{2}$ y La Petrona $4,2 \mathrm{~km}^{2}$. Esta última estuvo influenciada por el aumento de las precipitaciones dado que no tiene intervención humana, sino que es una de las típicas cubetas de origen eólico presentes en la Región Pampeana (FERRELLI; ALIAGA, 2015). El sur del área de estudio presentó la menor cantidad de cuerpos de agua aunque a diferencia de los otros eventos analizados, se localizaron una gran cantidad de cubetas aisladas con una superficie que osciló entre 50 y 250 ha. En el norte, la laguna Chasicó tuvo un área de $68 \mathrm{~km}^{2}$. La cantidad de cuerpos de agua mayores a $2 \mathrm{~km}^{2}$ fue de 18 durante este evento (Figura 8). Finalmente, es importante destacar que la estructura y el funcionamiento de las lagunas pampeanas pueden explicarse por su geomorfología, régimen climático, drenajes ubicados en suelos naturalmente ricos en nutrientes y por las modificaciones humanas en el uso de la tierra y el agua. Es posible entonces caracterizarlas sintéticamente como lagos de llanura, someros, eutróficos o hipertróficos y con tiempo de permanencia del agua y salinidad altamente variables (QUIRÓS et al., 2002). 
Efectos de eventos El Niño y La Niña sobre las lagunas del sur de la Región Pampeana (Argentina)

Tabla 6 - Caracterización de la precipitación en un año lluvioso según los métodos $\mathrm{N}$. relación con la tendencia central (Normal), IEP. Índice Estandarizado de Precipitación, Q. Método de Quintiles

\begin{tabular}{|l|c|c|c|c|}
\hline \multirow{2}{*}{$\begin{array}{c}\text { Estaciones } \\
\text { Meteorológicas }\end{array}$} & \multicolumn{4}{|c|}{ Evento E1 Niño (2014) } \\
\cline { 2 - 5 } & Pp anual & N & IEP & Q \\
\hline Viedma & 574 & Superior & Húmedo & Muy Lluvioso \\
\hline Escuela N'31 & 574 & Superior & Húmedo & Muy Lluvioso \\
\hline Villalonga & 654 & Superior & Muy Húmedo & Muy Lluvioso \\
\hline Hilario Ascasubi & 558 & Superior & Muy Húmedo & Muy Lluvioso \\
\hline TGS & 760 & Superior & Muy Húmedo & Muy Lluvioso \\
\hline Teniente Origone & 777 & Superior & Muy Húmedo & Muy Lluvioso \\
\hline Emilio Lamarca & 780 & Superior & Muy Húmedo & Muy Lluvioso \\
\hline Colonia Triaco & 705 & Superior & Extremadamente Húmedo & Muy Lluvioso \\
\hline Colonia Lote 6 & 694 & Superior & Extremadamente Húmedo & Muy Lluvioso \\
\hline Bahía Blanca & 816 & Superior & Muy Húmedo & Muy Lluvioso \\
\hline
\end{tabular}

Fuente: Elaboración propia.

\section{CONCLUSIONES}

A partir del análisis realizado es posible concluir que, a medida que aumenta la aridez del ambiente, los eventos extremos secos son más intensos. La región de estudio se ve influenciada más por los eventos La Niña que El Niño. Durante este último, si bien las precipitaciones son mayores, la duración de los períodos húmedos y su intensidad son menores que las sequías ocurridas durante La Niña. Aún así, ambos eventos generaron variaciones pluviométricas que ocasionaron variaciones espacio-temporales en el agua superficial.

El método ISODATA permitió distinguir los cuerpos de agua del resto de las coberturas de la tierra dado que se basan en los valores de radiancia. Este parámetro es mucho menor en las lagunas (como resultado de su mayor absorción) y, por lo tanto, este tipo de clasificación fue útil para el estudio de la dinámica espacial de los cuerpos de agua. No se observaron cambios significativos en el área de aquellos cuerpos de agua de origen tectónico, como la laguna Chasicó y aquellos con manejo antrópico como la laguna La Salada. La Petrona presentó un área que mantuvo una estrecha relación con la cantidad de precipitación. Se observaron modificaciones en la cantidad de agua superficial disponible durante distintos eventos pluviométricos extremos. En el año seco, la disponibilidad de agua fue menor que en el normal y el húmedo. El año normal sirvió como referencia para calcular la variación en la cantidad de agua superficial del área de estudio.

En la zona seca de la Región Pampeana los eventos El Niño y La Niña afectan la distribución de las precipitaciones y por lo tanto a la disponibilidad de agua en superficie. 
Efectos de eventos El Niño y La Niña sobre las lagunas del sur de la Región Pampeana (Argentina)

Sobre una región que tiende a la aridez, las sequías pueden producir efectos nocivos sobre el ambiente y afectar a la salud de la población. Por lo tanto, la información generada en este trabajo permitirá contribuir con planes de manejo sustentable del territorio orientados a mejorar la calidad de vida de la población y beneficiar el ambiente.

\section{AGRADECIMIENTOS}

Se agradece al Consejo Nacional de Investigaciones Científicas y Técnicas por la financiación del presente trabajo. Además, al Servicio Meteorológico Nacional (Argentina), al Instituto Nacional de Tecnología Agropecuaria (Argentina) y al USGS (Estados Unidos) por los datos brindados para la realización de este trabajo.

\section{REFERENCIAS}

ACEITUNO, P. On the functioning of the Southern Oscillation in the South American sector. Part I: Surface climate. Monthly Weather Review, Estados Unidos, v. 116, n. 3, p. 505-524, 1988.

ALIAGA, V. S.; FERRELLI, F.; ALBERDI-ALGARAÑAZ, E. D.; BOHN, V. Y.; PICCOLO, M. C. Distribución y variabilidad de la precipitación en la región pampeana argentina. Cuadernos de Investigación Geográfica, España, v. 42, n. 1, p. 261-280, 2016 .

; FERRELLI, F.; BOHN, V. Y.; PICCOLO, M. C. Utilización de imágenes satelitales para comprender la dinámica lagunar en la Región Pampeana. Revista de Teledetección, España, v. 46, p. 133-146, jun. 2016b.

ARCAYA, N. D.; CASTAÑEDA, C.; HERRERO, J.; LOSADA, J. A. Cartografía de coberturas asociadas a las fluctuaciones de la laguna de Gallocanta. Revista de Teledetección, España, v. 24, p. 61-65, dic. 2005.

BOHN, V. Y. Geomorfología e hidrografía de las lagunas del sur de la provincia de Buenos Aires. 2009. 224 f. Tesis (Doctorado en Geografía) - Departamento de Geografía y Turismo, Universidad Nacional del Sur, Argentina, 2009.

.; DELGADO, A. L.; PICCOLO, M. C.; PERILlO, G. M. E. Assessment of climate variability and land use effect on shallow lakes in temperate plains of Argentina. Environmental Earth Science, v. 75, n. 9, p. 1-15, 2016.

BOLOGNESI, E. Análisis de criterios para clasificar totales mensuales de precipitación aplicados a series de la República Argentina. En: CENTRO ARGENTINO DE METEORÓLOGOS. Meteorológica, Buenos Aires, 1971. 
CARMONA, F.; RIVAS, R.; THOMAS, L.; MARINO, B. Caracterización espectral del estuario del Río Quequén Grande por medio de imágenes Landsat. En: RIVAS, R.; CARMONA, F.; OCAMPO, D. (Org.). Teledetección: recientes aplicaciones en la Región Pampeana. Argentina: Martin, 2011. p. 11-29.

CHUVIECO, S. E. Teledetección ambiental: la observación de la tierra desde el espacio. España: Ariel Ciencia, 2002.

DELGADO, A. L. Estudio integrado ambiental de la plataforma continental interior y media de la zona de El Rincón, Argentina. 2013. 191 f. Tesis (Doctorado en Geografía) - Departamento de Geografía y Turismo, Universidad Nacional del Sur, Argentina, 2013.

EDWARDS, D. C.; MCKEE, T. B. Characteristics of 20th Century Drought in the United States at Multiple Time Scales. Colorado, E.E.U.U: Atmospheric Science, 1997. p. $1-30$.

FERRELLI, F. La sequía 2008-2009 en el Sudoeste de la provincia de Buenos Aires (Argentina). Ecosistemas: Revista Científica y Técnica de Ecología y Medio Ambiente, España, v. 2, n. 1-2, p. 235-238, 2012.

.; BOHN, V. Y.; PICCOLO, M. C.; Aplicación de geotecnologías al estudio de las precipitaciones y su relación con las coberturas del suelo (Pcia de Buenos Aires, Argentina). GeoFocus: Revista Internacional de Ciencia y Tecnología de la Información Geográfica, España, v. 11, p. 355 -374, 2011.

.; BOHN, V. Y.; PICCOLO, M. C. Variabilidad de la precipitación y ocurrencia de eventos secos en el sudoeste de la provincia de Buenos Aires (Argentina). En: JORNADAS NACIONALES DE GEOGRAFÍA FÍSICA, 9., Bahía Blanca, AR, 2012. Anais... Bahía Blanca, AR: Departamento de Geografía y. Turismo - UNS, 2012. p. 15-28.

.; ALIAGA, V. S. Variabilidad de las precipitaciones y sus efectos sobre la respuesta espacio-temporal de cuerpos de agua en la Región Pampeana, Argentina. 2015. 81 pp. Trabajo de aplicación final (Especialización en teledetección y Sistemas de Información Geográfica aplicados al estudio del medio ambiente) - Universidad Nacional de Luján, Argentina, 2015.

.; BUSTOS, M. L.; HUAMANTINCO-CISNEROS, M. A.; PICCOLO, M.. C. Utilización de imágenes satelitales para el estudio de la distribución térmica en distintas coberturas del suelo de la ciudad de Bahía Blanca (Argentina). Revista de Teledetección, España, v. 44, p. 31-42, 2015.

.; BUSTOS, M. L.; PICCOLO, M.C.; HUAMANTINCO-CISNEROS, M. A.; PERILLO, G. M. E. Downscaling de variales climáticas a partir del Reanálisis NCEP/NCAR en el sudoeste de la provincia de Buenos Aires (Argentina). Papeles de Geografía, España, v. 62, p. 21-33, 2016.

GERTEN, D.; ADRIAN, R. Climate-driven changes in spring plankton dynamics and the sensitivity of shallow polymictic lakes to the North Atlantic Oscillation. Limnology and Oceanography, Estados Unidos, v. 45, n. 5, p. 1058-1066, jul. 2000. 
.; ADRIAN, R. Differences in the persistency of the North Atlantic Oscillation signal among lakes. Limnology and Oceanography, Estados Unidos, v. 46, n. 02, p. 448455, mar. 2001.

GORDON, L. J.; PETERSON, G. D.; BENNETT, E. M. Agricultural modifications of hydrological flows create ecological surprises. Trends in Ecology Evolution, Estados Unidos, v. 23, n. 4, p. 211-219, abr. 2008.

GRIMM, A. M.; BARROS, V. R.; DOYLE, M. E. Climate variability in Southern South America associated with El Niño and La Niña events. Journal of Climate, Estados Unidos, v. 13, n. 1, p. 35-58, ene. 2000.

HOUGHTON, R. A. Is carbon accumulating in the northern temperate zone? Global Biogeochem Cycles, Estados Unidos, v. 7, n. 3, p. 611-617, sept. 1993.

LEHNER, B.; DÖLL, P.; ALCAMO, J.; HENRICHS, T.; KASPAR, F. Estimating the impact of global change on flood and drought risks in Europe: a continental, integrated analysis. Climatic Change, v. 75, n. 3, p. 273-299, abr. 2006.

MAGRIN, G. O.; TRAVASSO, M. I.; RODRÍGUEZ, G. R. Changes in climate and crop production during the 20th century in Argentina. Climatic Change, v. 72, n. 1, p. 229-249, sept. 2005.

MOOIJ, W. M.; HULSMANN, S.; DE SERERPONT DOMIS, L. N.; NOLET, B. A.; BODELIER, P. L. E.; BOERS, P. C. M.; PIRES, M. L. D.; GONS, H. J.; IBELINGS, B. W.; NOORDHUIS, R.; PORTIELJE, R.; WOLFSTEIN, K.; LAMMENS, E. H. R. R. The impact of climate change on lakes in the Netherlands: a review. Aquatic Ecology, v. 39, n. 4, p. 381-400, dic. 2005.

MOREIRA E. E.; PAULO, A. A.; PEREIRA, L. S.; MEXIA, J. T. Analysis of SPI drought class transition using loglinear models. Journal of Hydrology, Estados Unidos, v. 331, n. 1-2, p. 349-359, nov. 2006.

NOSETTO, M. D.; JOBBAGY, E.G., PARUELO, J.M. Land-use change and water losses: the case of grassland afforestation across a soil textural gradient in central Argentina. Global Change Biology, v. 11, n. 7, p. 1101-1117, jul. 2005.

PALMER, M. A.; REIDY, C. A.; NILSSON, C.; FLÖRKE, M.; ALCAMO, J.; LAKE, P. S. BOND N. Climate change and the world's river basins: anticipating management options. Frontiers in Ecology and the Environment, Estados Unidos, v. 6, n. 2, p. 8189, mar. 2008.

QUIRÓS, R.; RENNELLA, A.; BOVERI, M.; ROSSO, J.; SOSNOVSKY, A. Factores que afectan la estructura y el funcionamiento de las lagunas pampeanas. Ecología Austral, Córdoba, v. 12, n. 2, p. 175-185, dic. 2002.

SÁNCHEZ, R.; PEZZOLA, A.; CEPEDA, J. Caracterización edafoclimática del área de influencia del INTA EEA Hilario Ascasubi. Buenos Aires, Argentina: Instituto Nacional de Tecnología Agropecuaria/EEA Hilario Ascasubi, 1998. 
SCIAN, B. Variabilidad de las condiciones hídricas en la región semiárida pampeana, Argentina. GEOACTA, Buenos Aires, v. 27, p. 30-52, 2002.

., LABRAGA, J. C.; REIMERS, W.; FRUMENTO, O. Characteristics of large-scale atmospheric circulation related to extreme monthly rainfall anomalies in the Pampa Region, Argentina, under non-ENSO conditions. Theoretical Applied Climatology, v. 85, n. 1, p. 89-106, mayo. 2006.

SONG, C.; WOODCOCK, C. E.; SETO, K. C.; LENNEY, M. P.; MACOMBER, S. A. Classification and change detection using Landsat TM data: when and how to correct atmospheric effects? Remote Sensing Of Environment, v. 75, n. 2, p. 230-244, feb. 2001.

SWAIN, P. H. Pattern recognition: a basis for remote sensing data analysis (LARS information note 111572). West Lafayette, Indiana: The Laboratory for Applications of Remote Sensing, Pardue University, 1973.

ZHANG, Q.; XU, C.; ZHANG, Z. Observed changes of drought/wetness episodes in the Pearl River basin, China, using the standardized precipitation index and aridity index. Theoretical and applied climatology, v. 98, n. 1, p. 89-99, sept. 2009.

ZHAI, J.; SU, B.; GAO, C.; JIANG, T. Spatial Variation and Trends in PDSI and SPI Indices and Their Relation to Streamflow in 10 Large Regions of China. Journal of Climate, Estados Unidos, v. 23, n. 3, p. 649-663, feb. 2010.

Recebido para avaliação em 07/07/2016

Aceito para publicação em 08/11/2016 